\title{
THE DEVELOPMENT OF TEXTURE IN COPPER AND COPPER-ZINC ALLOYS
}

\author{
J. S. KALLEND and G. J. DAVIES \\ Department of Metallurgy, University of Cambridge \\ Pembroke Street, Cambridge, England
}

(Received October 30, 1971)

\begin{abstract}
The crystallite orientation distribution function has been determined for cold-rolled copper, copper-10 per cent zinc and copper-30 per cent zinc ( $\alpha$-brass) at cold reductions of $0,20,40,60,80,90$ and 95 per cent. The copper texture exhibits a steady development and contains a tube of orientations between limits which have previously been shown to be stable during multiple slip processes $(\{110\}\langle 112\rangle$ to $\{4411\}\langle 11118\rangle)$. The textures of the copper-zinc alloys both show a similar initial development to that of copper but a transition occurs above a reduction of about 40 per cent. This indicated that an additional deformation mode had become active. The features of the transition are consistent with those expected if the additional deformation mode were mechanical twinning. The development of the basic texture (pure-metal type) is in agreement with predictions based on the assumption of multiple slip conditions incorporating a considerable amount of cross-slip.
\end{abstract}

\section{INTRODUCTION}

It has long been recognised that the rolling texture of copper and similar face-centred cubic metals is different from that of silver, $\alpha$-brass and many face-centred cubic alloys. This difference has led to the classification of the textures as the "pure-metal" type and "alloy" type, respectively. The alloy texture is frequently characterised as being based on the orientation $\{110\}\langle 112\rangle$. The pure metal texture is more complex but has been considered to contain orientations near $\{112\}\langle 111\rangle$ which are usually absent from the alloy texture. Since the rolling texture of a metal reflects the operative deformation mechanisms the differences in rolling texture have attracted a great deal of attention. Detailed reviews have been presented by Dillamore and Roberts ${ }^{1}$ and $\mathrm{Hu}$ et al. ${ }^{2}$.

In many cases it has been shown that a transition from the "pure-metal" texture to the "alloy" texture can be brought about by changes in composition or rolling conditions. For instance, Smallman $^{3}$ and Liu and Richman ${ }^{4,5}$ have shown that progressive additions of alloying elements to copper give rise to the transition. Similarly, it has been shown that metals and alloys which develop the pure metal texture when rolled at room temperature form an alloy texture after deformation at lower temperatures, ${ }^{3,6}$ while those which develop the alloy texture at room temperature develop the pure metal texture at elevated tempertures. $^{7,8}$

A texture transition has also been observed in copper- $5 \%$ zinc rolled at different rates. ${ }^{9}$ It was found that high deformation rates favoured the development of the alloy texture.

The observations of texture transitions have been related to the stacking fault energy by a number of workers. ${ }^{7,8,10,11}$ The pure metal texture is normally associated with high stacking fault energies and the alloy texture with low stacking fault energies. This correlation between texture and stacking fault energy has, in practice, been used to determine values of the stacking fault energy. ${ }^{12}$

A number of studies have shown that in both classes of materials the initial texture development is similar, ${ }^{2,13,14}$ with deviations into the different types at higher reductions.

The accumulation of evidence relating to the texture transition has given rise to a number of theories of texture development.

a) Smallman and Green ${ }^{11}$ and Dillamore and Roberts ${ }^{15}$ proposed that both the difference between the pure metal texture and the alloy texture, and the transition from one type to the other, were the result of differences in the crossslip behaviour of glide dislocations. The hypothesis was that the alloy-type texture developed first and was transformed by cross-slip dependent reorien- 
tation to the pure metal type. The ease with which cross-slip can occur increases as the stacking fault energy increases (Seeger ${ }^{16}$ ) and thus the theory predicted that high stacking fault energies would lead to the development of the pure metal texture. Since the stacking fault energy of a metal is normally lowered by alloy additions ${ }^{17}$ and since cross-slip is a thermally activated process, the cross-slip theory appeared to be consistent with both the composition dependence and the temperature dependence of the texture transition.

Subsequent observations, however, have cast doubts on this theory in its original form. Firstly, it is clear that abundant cross-slip occurs in $\alpha$-brass (which forms the alloy-type texture) even at low deformations. ${ }^{18}$ Secondly, the sequence of texture development reported by $\mathrm{Hu}$ et al. ${ }^{2}$ and Dillamore et $a .^{13}$ is contrary to that predicted by the crossslip theory.

Leffers ${ }^{18}$ later proposed a modified cross-slip theory. This theory required that the grain interiors deform by single slip to give the alloy texture, a requirement in conflict with the observation that profuse amounts of multiple slip occur in $\alpha$-brass ${ }^{20}$ although it develops the alloy texture. Furthermore, this theory predicted rapid rotations to stable end orientations for materials that do not cross-slip, whereas, in practice, one of the most noteworthy features of the alloy texture is that it is not as sharp as the pure metal texture at the same reduction. $1,21,22$

Despite these difficulties and because of individual differences in the textures of metals developing the pure metal texture, Dillamore et al. ${ }^{13}$ concluded that cross-slip plays an important role in texture development. This has been further substantiated by Dillamore ${ }^{23}$ who concluded that, through its influence on the different deformation mechanisms, cross-slip is the rate-controlling process in texture development.

b) Haessner ${ }^{24}$ proposed a theory in which the alloy-texture was the end point for rotations produced by normal $\{111\}\langle 110\rangle$ slip whereas the pure metal texture resulted from normal slip together with slip on $\{001\}$ planes ("cubic slip"). This proposition is essentially the same as that put forward earlier by Richards and $\mathrm{Pugh}^{25}$. Cubic slip, however, is geometrically equivalent to equal proportions of primary slip and cross-slip ${ }^{1}$ and thus the macroscopic predictions of the closs-slip theory and the cubic slip theory are similar. In addition is must be pointed out that there is little direct evidence of cubic slip in face-centred cubic crystals except under extreme circumstances (Beevers and Honeycombe ${ }^{26}$ ).

c) It has been shown by Wassermann ${ }^{27}$ that if mechanical twinning is an available mode of deformation in addition to normal slip the components in the pure metal texture near $\{112\}$ $\langle 111\rangle$ can be transformed to $\{552\}\langle 115\rangle$ by twinning and thence by further slip to $\{110\}$ $\langle 001\rangle$. In contrast the major component of the alloy texture $\{110\}\langle 112\rangle$, retains its orientation during deformation. The predictions of the twinning theory have been largely supported by experiments on single crystals, $2,28,29$ although Leffers $^{19}$ has questioned the validity of single crystal results when applied to polycrystalline aggregates. There is considerable direct evidence of twinning in low stacking fault energy facecentred cubic metals ${ }^{2,14,20}$ and contrary to the arguments of Dillamore and Roberts ${ }^{1}$ there are textural data which provide additional support. For instance, the observations that the alloytexture forms from the developing pure metal texture $e^{2,13}$ is in accord with the twinning theory. The results of Williams ${ }^{30} \dagger$ and Chin et al. ${ }^{31}$ also provide support.

d) Observations made by $\mathrm{Hu}$ et $a l .{ }^{8}$ led them to conclude that the texture transition was due to stacking fault formation and was caused by the change in deformation faulting behaviour per se. Using this hypothesis differences in the pure metal texture and the alloy texture were partially accounted for. The theory required some constraint to be exercised over the mobility of partial dislocations to avoid it degenerating into the twinning theory. As a consequence, the amount of deformation available by this mechanism is limited and it has been argued ${ }^{13}$ that this limitation invalidates the theory.

e) A theory for face-centred cubic textures based on dislocation interaction has been proposed by $\mathrm{Liu}^{32}$. This theory is highly hypothetical and the validity of the assumptions involved is difficult to examine. It must be noted, however, that the threedimensional analyses of crystallite orientation distributions in copper ${ }^{30,33}$ provide data contrary to those cited in support of Liu's theory. ${ }^{34}$ The

\footnotetext{
† These results are misinterpreted in the original paper because of some confusion between the initial and final orientations of the twinning process.
} 
hypothesis has also been questioned in detail by Dillamore. ${ }^{35}$

There are probably elements of truth in all the theories proposed to explain the deformation texture of face-centred cubic metals. The present paper examines the development of the deformation texture during the cold-rolling of metals which develop the pure metal texture (copper) and the alloy texture ( $\alpha$-brass), using the three-dimensional crystallite orientation distribution function analysis technique. In addition a metal of intermediate behaviour (copper-10 per cent zinc, gilding metal) has also been examined. The analytical technique yields detailed information on the orientation distribution of crystals in the rolled sheets and this information is examined with regard to the different proposals.

A complete analysis of rolling texture formation based upon theories of multiple slip in polycrystals ${ }^{36,37,38}$ has been made by the authors and will be published elsewhere ${ }^{51}$. This analysis takes account, in a similar way to the analyses of Chin et $a .^{31}$, Chin $^{39}$ and Dillamore and Stoloff ${ }^{40}$, as far as possible, of the effects of cross-slip and twinning. Where appropriate the results of this analysis will be related to the present results.

\section{EXPERIMENTAL PROCEDURES}

Three alloys of commercial purity were studied. These were nominally pure copper, copper-10 wt. per cent zinc (gilding metal) and copper-30 wt. per cent zinc ( $\alpha$-brass). For all these alloys the principal impurity was lead ( $\neq 0.5$ per cent). The material was supplied in sheets $3.2 \mathrm{~mm}(0.125 \mathrm{in})$ thick, having followed a typical production schedule of hot-rolling to within 50 per cent of size followed by cold rolling with an intermediate and final anneal at $600^{\circ} \mathrm{C}$. The initial grain size was of the order of $0.035 \mathrm{~mm}$ in all cases.

Samples were rolled in a two-high mill with 8 -inch diameter rolls using guides to ensure constancy of rolling direction. The alloys were reduced from $3.2 \mathrm{~mm}$ to $0.5 \mathrm{~mm}$ in steps of $0.5 \mathrm{~mm}$, from $0.5 \mathrm{~mm}$ to $0.125 \mathrm{~mm}$ in steps of $0.125 \mathrm{~mm}$ and then in steps of $0.025 \mathrm{~mm}$. Total nominal rolling reductions of $0,20,40,60,80,90$ and 95 per cent were made for each alloy composition.

$\mathrm{X}$-ray pole figure measurements were made on composite specimens prepared using the techniques of Leber ${ }^{41}$ and Elias and Heckler. ${ }^{42}$ This technique enables a complete quadrant of a conventional pole figure to be obtained using the Schultz reflection technique. ${ }^{43}$ The rolled sheets were chemically polished before preparing the composite specimens, to remove surface material. In making the composite the method of Lopata and $\mathrm{Kula}^{44}$ was adopted to ensure that a true average was obtained over all the quadrants of the pole figure. A Siemens texture goniometer was used with filtered copper $K \alpha$ radiation. Measurements were made on the $\{111\},\{200\}$ and $\{220\}$ reflections from each composite specimen. The pole figure data were normalised by setting the integrated pole density over the whole reference sphere to $4 \pi$. The data were analysed by computer and pole figures were plotted automatically using a curve plotter controlled by a contouring programme.

Conventional pole figures show the variation in pole density with pole orientation for a selected set of crystal planes. A more detailed description of the texture can be obtained by deriving the crystallite orientation distribution function using a procedure such as that described by $\mathrm{Roe}^{45}$. In this procedure the pole distribution (obtained from the pole figure) is expanded in a series of spherical harmonics and the simultaneous equations connecting the coefficients of these harmonics with the coefficients of a series of generalised spherical harmonics are solved. This latter series forms the expansion of the crystallite orientation distribution function, $w(\psi, \xi, \phi)$, given by

$$
\begin{aligned}
w(\psi, \xi, \phi)= & \sum_{l=0}^{\infty} \sum_{m=l}^{l} \sum_{n=l}^{l} W_{l m n} Z_{l m n}(\xi) \exp (-i m \psi) \\
& \times \exp (-i n \phi)
\end{aligned}
$$

where $W_{l m n}$ are the coefficients and $Z_{l m n}(\xi)$ is a generalisation of the associated Legendre function. The crystallite orientation distribution function expresses the probability of a crystallite having an orientation described by the Euler angles $\theta\left(=\cos ^{-1} \xi\right), \psi$ and $\phi$ (Figure 1). The coefficients of the distribution function were determined to the twentieth order at which stage it was found that the coefficients became zero to within experimental error. This was in agreement with the results of other workers. ${ }^{33,46}$

The results of analyses of crystal orientation distributions are normally represented by plotting the probabilities in Eulerian space and taking constant sections of one of the Euler angles, most 
usually constant- $\phi$ sections. A specific ideal orientation is represented by a single point in Eulerian space, with the angles $\theta$ and $\phi$ being determined by the indices of the rolling plane and

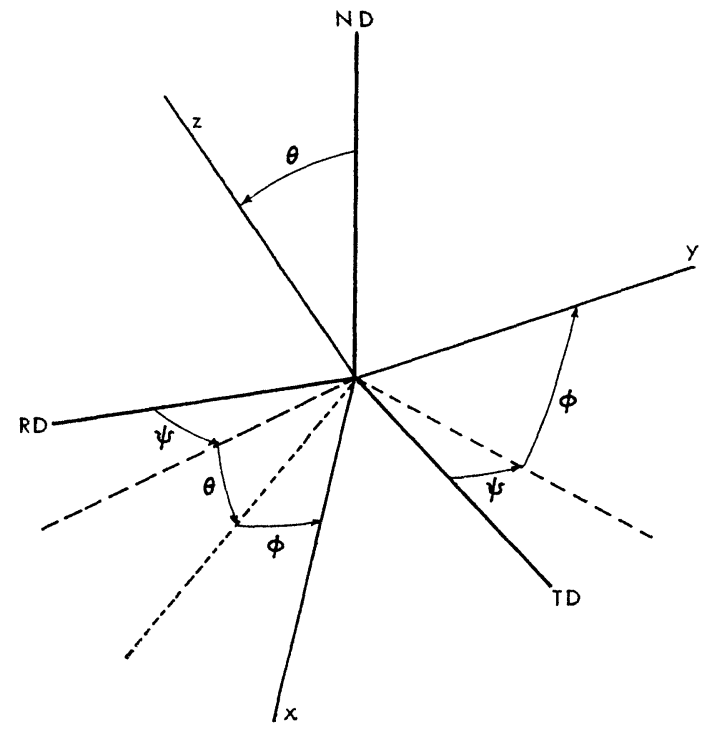

FIGURE 1 The Euler angles $\psi, \theta, \phi$, relating the specimen axes, RD (rolling direction), TD (transverse direction), ND (normal direction) with the crystal axes, $x, y, z$.

the angle $\psi$ by those of the rolling direction. For cubic crystals all the components of the most general form of ideal orientation are represented by at most three points in the Eulerian space bounded by the limits

$$
0 \leqq \theta \leqq \pi / 2 \quad 0 \leqq \psi \leqq \pi / 2 \quad 0 \leqq \phi \leqq \pi / 2
$$

This limitation is a consequence of the inherent symmetry of the cubic system. Charts indicating the Euler angles corresponding to low index ideal orientations in the cubic system have been published elsewhere. ${ }^{47}$ Table I gives a list of the Euler angles corresponding to various ideal orientations which may be of use in the interpretation of the crystallite orientation distribution function plots given in Section 3. In making these plots the crystallite distribution function was determined at each of 2560 orientations, corresponding to a $6^{\circ}$ by $6^{\circ}$ by $10^{\circ}$ grid in Eulerian space.

When necessary the volume fraction of crystallites having an orientation within a given region of Eulerian space can be determined by integration of the distribution function over that region. ${ }^{48}$ The extent to which the crystallites have taken up a given ideal orientation is thus easily investigated. If, in addition, an overall measure of the severity of the texture is required this can be made by

TABLE I

Euler angles for given ideal orientations

\begin{tabular}{|c|c|c|c|c|}
\hline \multicolumn{2}{|c|}{ Ideal orientation } & \multicolumn{3}{|c|}{ Euler angles } \\
\hline$h k l$ & $u v w$ & $\theta$ & $\phi$ & $\psi$ \\
\hline 110 & 112 & $\begin{array}{l}45 \\
45 \\
90\end{array}$ & $\begin{array}{r}0 \\
90 \\
45\end{array}$ & $\begin{array}{l}54.7 \\
54.7 \\
35.3\end{array}$ \\
\hline 110 & 001 & $\begin{array}{l}45 \\
45 \\
90\end{array}$ & $\begin{array}{r}0 \\
90 \\
45\end{array}$ & $\begin{array}{r}90 \\
90 \\
0\end{array}$ \\
\hline 112 & 111 & $\begin{array}{l}35.3 \\
65.9\end{array}$ & $\begin{array}{l}45 \\
63.4\end{array}$ & $\begin{array}{c}0 \\
50.8\end{array}$ \\
\hline 123 & 412 & $\begin{array}{l}57.7 \\
74.5 \\
35.7\end{array}$ & $\begin{array}{l}71.6 \\
56.3 \\
26.6\end{array}$ & $\begin{array}{l}75 \\
25.1 \\
43.1\end{array}$ \\
\hline 100 & 001 & $\begin{array}{r}0 \\
90 \\
90 \\
90 \\
90\end{array}$ & $\begin{array}{c}\phi+\psi=0 \\
0 \\
0 \\
90 \\
90\end{array}$ & $\begin{array}{r}90 \\
0 \\
90 \\
0 \\
90\end{array}$ \\
\hline 111 & 112 & $\begin{array}{l}54.7 \\
54.7\end{array}$ & $\begin{array}{l}45 \\
45\end{array}$ & $\begin{array}{r}0 \\
60\end{array}$ \\
\hline 552 & 115 & $\begin{array}{l}47.1 \\
74.2\end{array}$ & $\begin{array}{l}21.8 \\
45\end{array}$ & $\begin{array}{c}74.5 \\
0\end{array}$ \\
\hline 358 & 523 & $\begin{array}{l}59.7 \\
72.4 \\
36.1\end{array}$ & $\begin{array}{l}69.4 \\
58.0 \\
31.0\end{array}$ & $\begin{array}{l}68.1 \\
32.6 \\
31.6\end{array}$ \\
\hline 4411 & 11118 & $\begin{array}{l}27.2 \\
71.1\end{array}$ & $\begin{array}{l}45 \\
70.0\end{array}$ & $\begin{array}{c}0 \\
48.4\end{array}$ \\
\hline
\end{tabular}

summing the standard deviation of the orientation distribution function from random throughout Eulerian space. This defines a severity parameter (SP) given by

$$
(\mathrm{SP})^{2}=\frac{1}{8 \pi^{2}} \oint[w(\Omega)-1]^{2} d \Omega
$$

where $\Omega$ is a general orientation and random intensity has unit value. In the present case the development of the texture in the three materials was followed using this parameter. 


\section{RESULTS}

\subsection{Pole Figures}

$\{111\},\{200\}$ and $\{220\}$ pole figures were determined for the three materials at each of $0,20,40$, $60,80,90$ and 95 per cent rolling reduction. Pole figures for the $\{111\}$ reflections are given in Figures 2, 3 and 4 . The pole figures for the asreceived materials show that initially some texture was present. This was only significant for copper$10 \%$ zinc (Figure 3a), being similar to the subsequent rolling texture but not very well developed.

The series of pole figures are consistent with those of previous workers. ${ }^{2,14}$

\subsection{Orientation Distribution Functions}

Crystallite orientation distribution function plots were derived from the pole figures for the three materials and these are given in Figures 5, 6 and 7 for copper, copper- $10 \%$ zinc and copper- $30 \%$ zinc, respectively. Plots are presented for reductions of 40 per cent and 95 per cent onlyt since these effectively characterise the texture development in the different materials. Throughout the range of deformation the copper texture (Figure 5a,b) exhibits a continuous tube of high orientation density running between $\{110\}\langle 112\rangle$ and near $\{112\}\langle 111\rangle$. In fact, the tube ends at the $\{4411\}$ $\langle 11118\rangle$ orientation which is only $\sim 8$ degrees from $\{112\}\langle 111\rangle$. This end orientation has been predicted by Dillamore et al. ${ }^{13}$ Increasing deformation does not alter the basic form of the crystallite distribution, but serves to sharpen it.

The texture of copper $-10 \%$ zinc shows a similar initial development (Figure 6a). Above about 40 per cent reduction a depletion of orientations near $\{112\}\langle 111\rangle$ is apparent and in contrast to the copper, by 95 per cent reduction there is very little material left in this orientation (Figure 6b). At the same time as this depletion takes place there is a build up of orientation density in the $\{111\}$ $\langle 112\rangle,\{552\}\langle 115\rangle$ and $\{110\}\langle 001\rangle$ orientations. None of these orientations are significantly populated in copper at any reduction. It is also noteworthy that there is more spread in the texture of copper- $10 \%$ zinc than in copper (see Section 3.4).

+ Complete plots for the other reductions can be obtained from the authors.
The $\alpha$-brass texture (Figs. 7a, b) develops along the same lines as does that of the copper- $10 \%$ zinc. The depletion of orientations near $\{112\}$ $\langle 111\rangle$ is even more striking with little material left in this orientation by 80 per cent reduction. The appearance of material in the $\{111\}\langle 112\rangle,\{552\}$ $\langle 115\rangle$ and $\{110\}\langle 001\rangle$ orientations is well marked from 60 per cent reduction onwards. The brass texture is less well developed than that of either of the other materials.

\subsection{Effect of rolling reduction}

A number of the above points are clearly summarised in Figures 8(a) (b) (c) which show the variation of the orientation density with rolling reduction for various ideal orientations. These figures also illustrate a distinct difference between the two copper-zinc alloys. In copper- $10 \%$ zinc the orientation $\{123\}\langle 412\rangle$ develops continuously whereas it becomes static in copper- $30 \%$ zinc above about 60 per cent reduction.

TABLE II

Fraction of crystals (per cent) within $10^{\circ}$ of given ideal orientations

\begin{tabular}{lrrrrrrr}
\hline \multicolumn{1}{c}{ Orientation } & \multicolumn{6}{c}{ Reduction $(\%)$} \\
\hline Copper & 0 & 20 & 40 & 60 & 80 & 90 & 95 \\
& & & & & & & \\
$\{110\}\langle 112\rangle$ & 1.9 & 5.9 & 8.0 & 8.9 & 10.5 & 10.4 & 10.9 \\
$\{552\}\langle 115\rangle$ & 1.7 & 0.9 & 1.2 & 1.6 & 2.1 & 2.0 & 2.9 \\
$\{4411\}\langle 11118\rangle$ & 2.8 & 4.3 & 6.75 & 7.3 & 8.8 & 11.6 & 10.0 \\
& & & & & & & \\
& & & & & & & \\
Copper-10\% zinc & & & & & & & \\
& 0 & 20 & 40 & 60 & 80 & 90 & 95 \\
$\{110\}\langle 112\rangle$ & 4.7 & 6.0 & 6.9 & 7.8 & 8.9 & 10.4 & 13.5 \\
$\{552\}\langle 115\rangle$ & 1.1 & 0.9 & 1.8 & 3.3 & 4.4 & 5.4 & 5.6 \\
$\{4411\}\langle 11118\rangle$ & 3.0 & 3.9 & 4.0 & 3.4 & 2.4 & 2.2 & 1.8 \\
& & & & & & & \\
Copper-30\% zinc & & & & & & & \\
& 0 & 20 & 40 & 60 & 80 & 90 & 95 \\
$\{110\}\langle 112\rangle$ & 3.5 & 5.3 & 6.7 & 7.0 & 7.1 & 9.0 & 10.6 \\
$\{552\}\langle 115\rangle$ & 1.3 & 1.3 & 1.7 & 3.9 & 4.0 & 4.7 & 3.8 \\
$\{4411\}\langle 11118\rangle$ & 1.9 & 3.1 & 3.8 & 3.1 & 1.5 & 1.5 & 1.3 \\
\hline & & & & & & & \\
\hline
\end{tabular}

These results are quantified in Table II where the volume fraction (per cent) of crystallites within 10 degrees of the $\{110\}\langle 112\rangle,\left\{\begin{array}{lll}4 & 11\end{array}\right\}\langle 11118\rangle$ and $\{552\}\langle 115\rangle$ orientations are given for the three materials. This table also shows that the 
56

J. S. KALLEND AND G. J. DAVIES

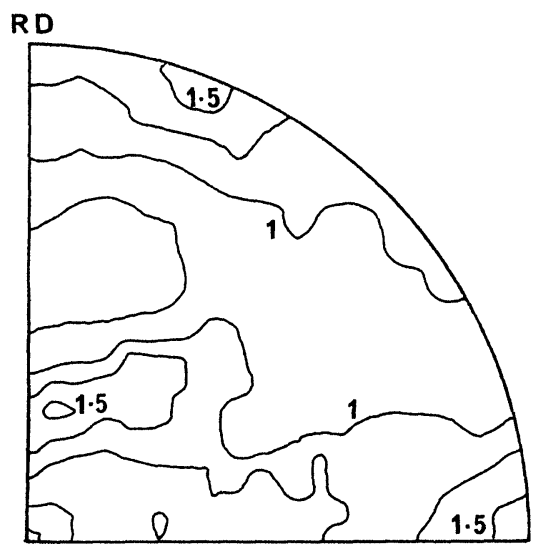

a



c

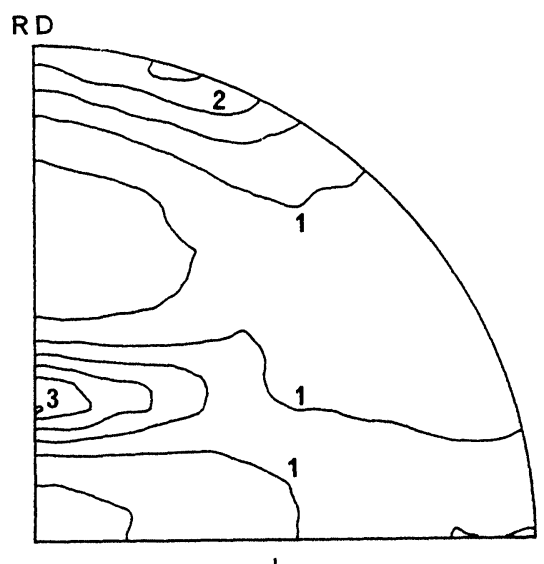

b

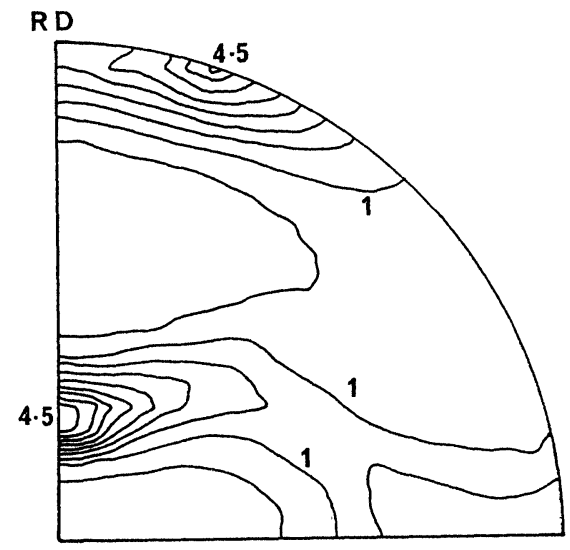

d

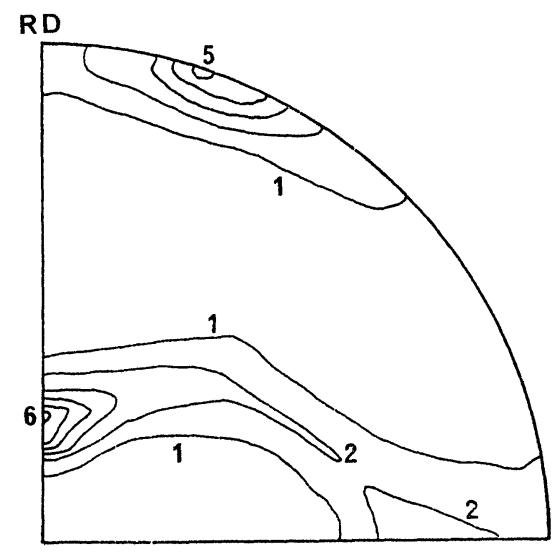

e

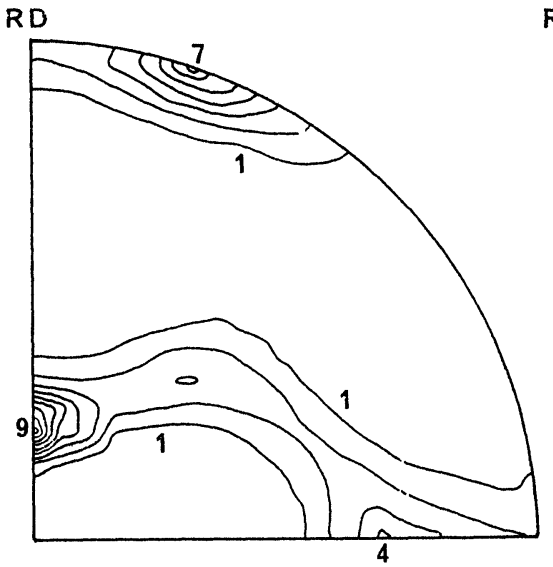

f

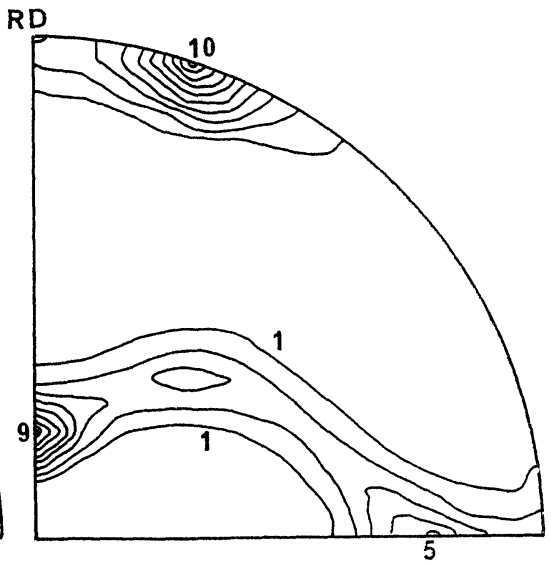

$\mathrm{g}$

FIGURE 2 X-ray pole figures for cold-rolled copper sheet, $\{111\}$ reflection (a) as received (b) $20 \%$ reduction (c) $40 \%$ reduction (d) $60 \%$ reduction (e) $80 \%$ reduction (f) $90 \%$ reduction (g) $95 \%$ reduction. 

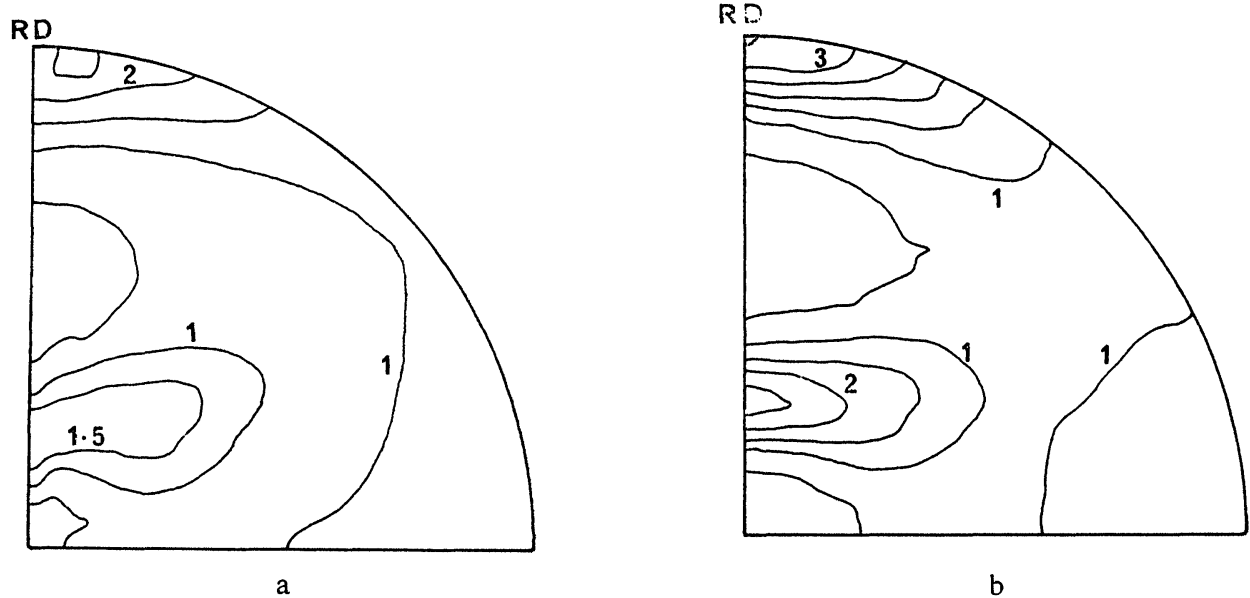

b
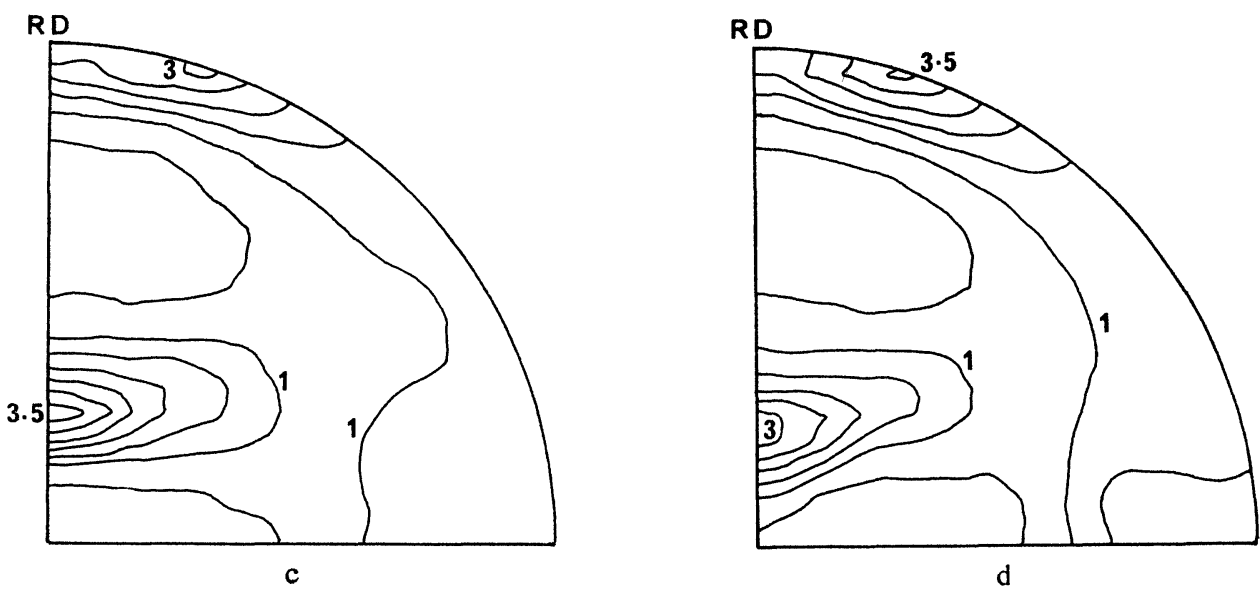



e

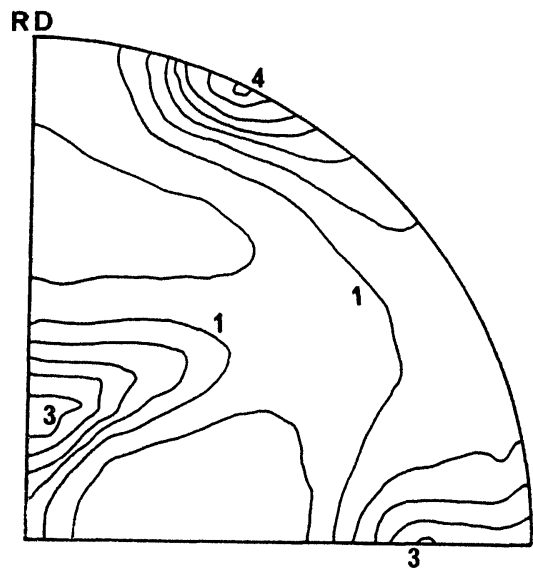

f

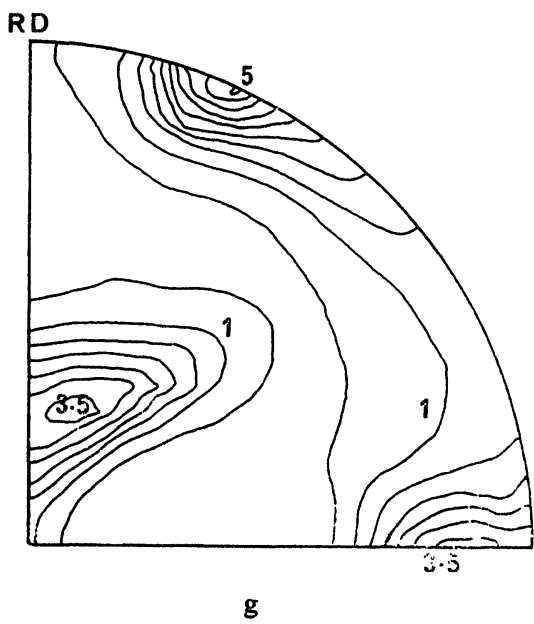

FIGURE 3 X-ray pole figures for cold-rolled copper-10 per cent zinc (gil ding metal), $\{111\}$ reflection (a) as received (b) $20 \%$ reduction (c) $40 \%$ reduction (d) $60 \%$ reduction (e) $80 \%$ reduction (f) $90 \%$ reduction (g) $95 \%$ reduction. 


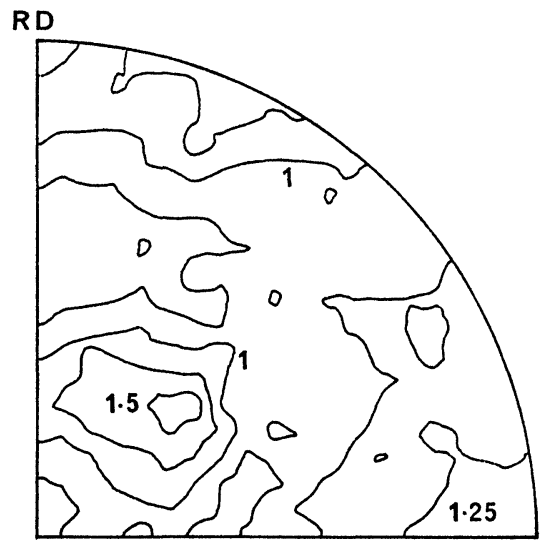

a

RD

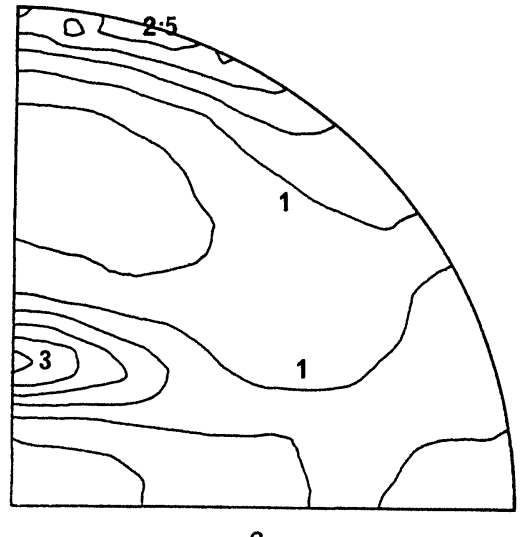

c

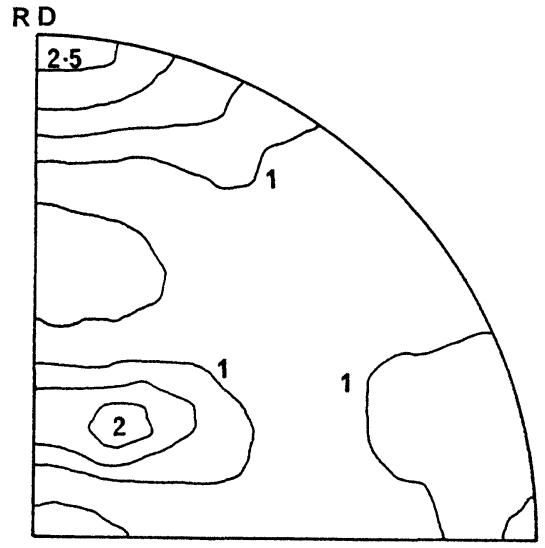

b

RD

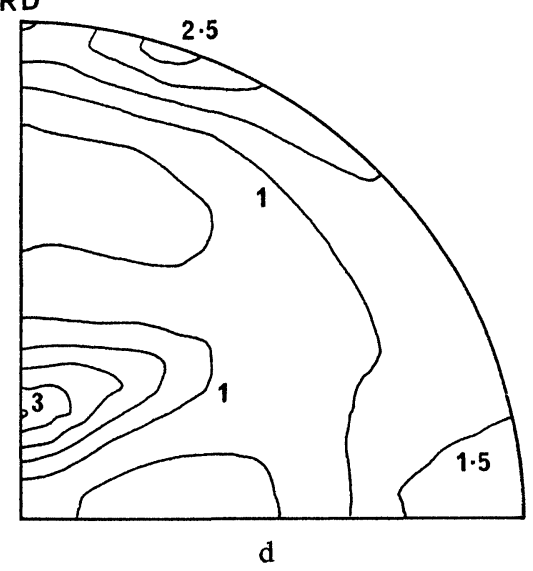

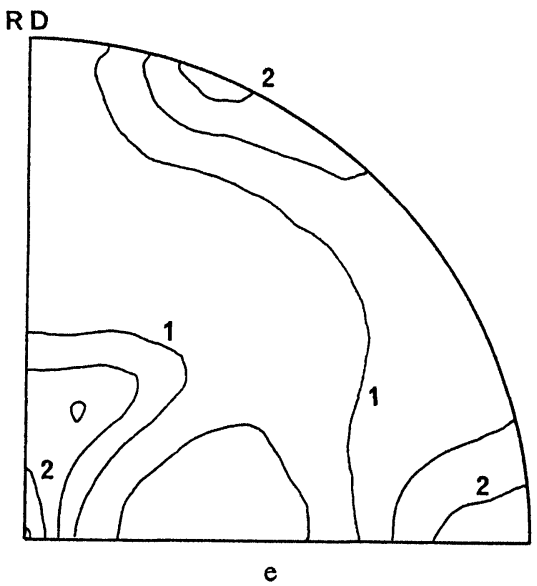
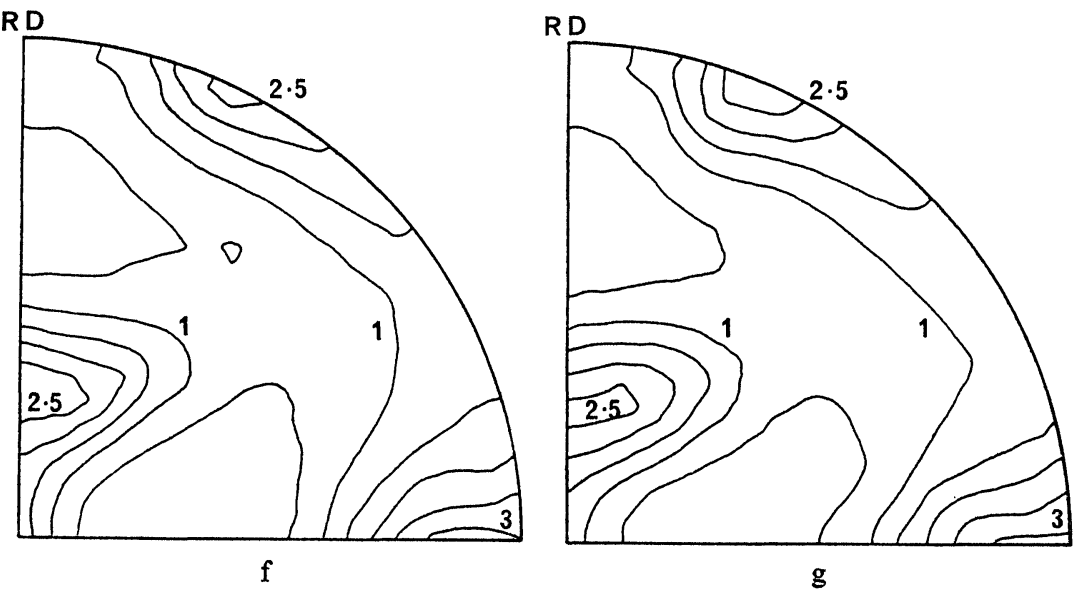

FIGURE 4 X-ray pole figures for cold-:olled copper-30 per cent zinc ( $\alpha$-brass), $\{111\}$ reflection (a) as received (b) $20 \%$ reduction (c) $40 \%$ reduction (d) $60 \%$ reduction (e) $80 \%$ reduction (f) $90 \%$ reduction (g) $95 \%$ reduction. 

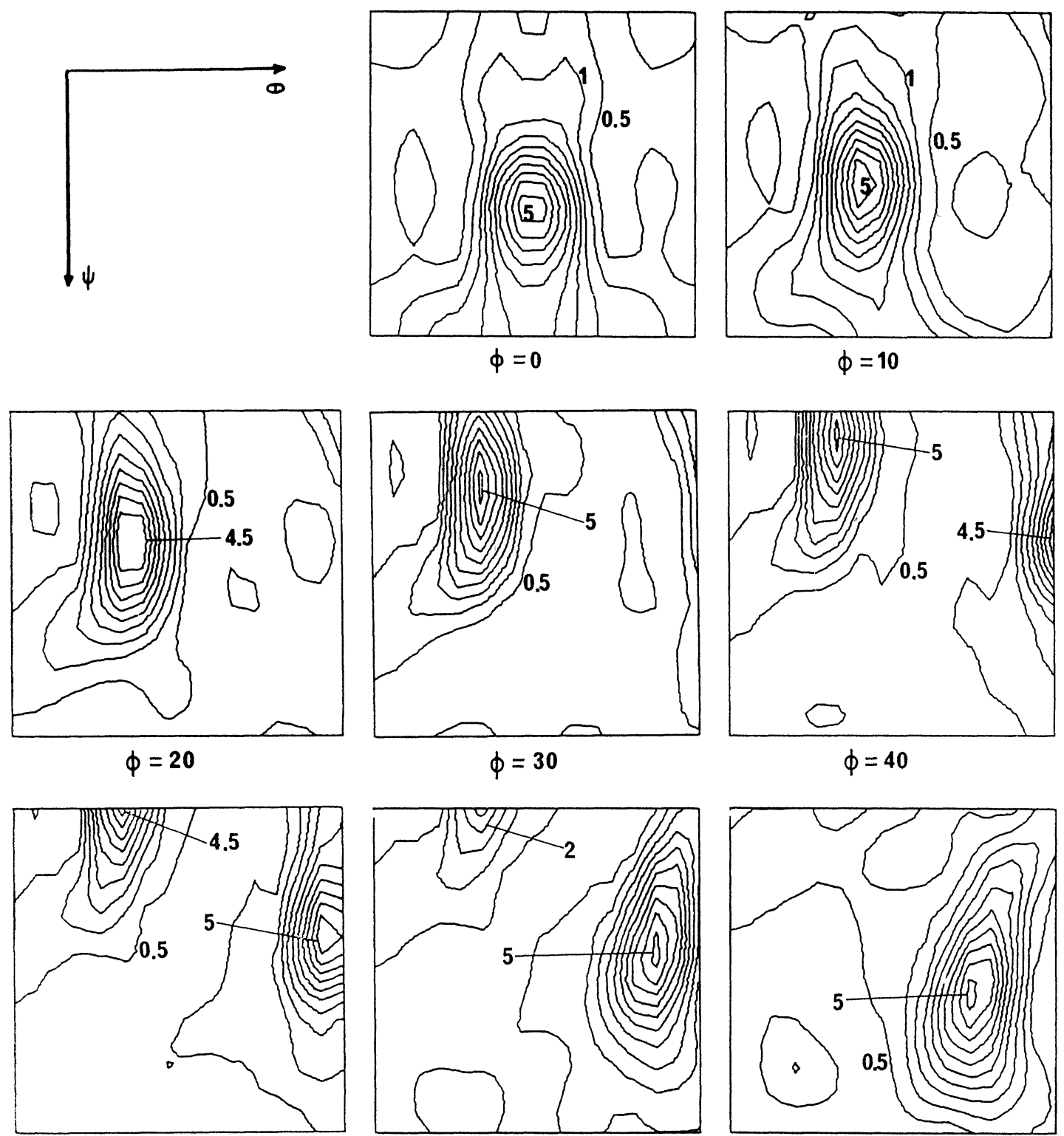

$\phi=50$
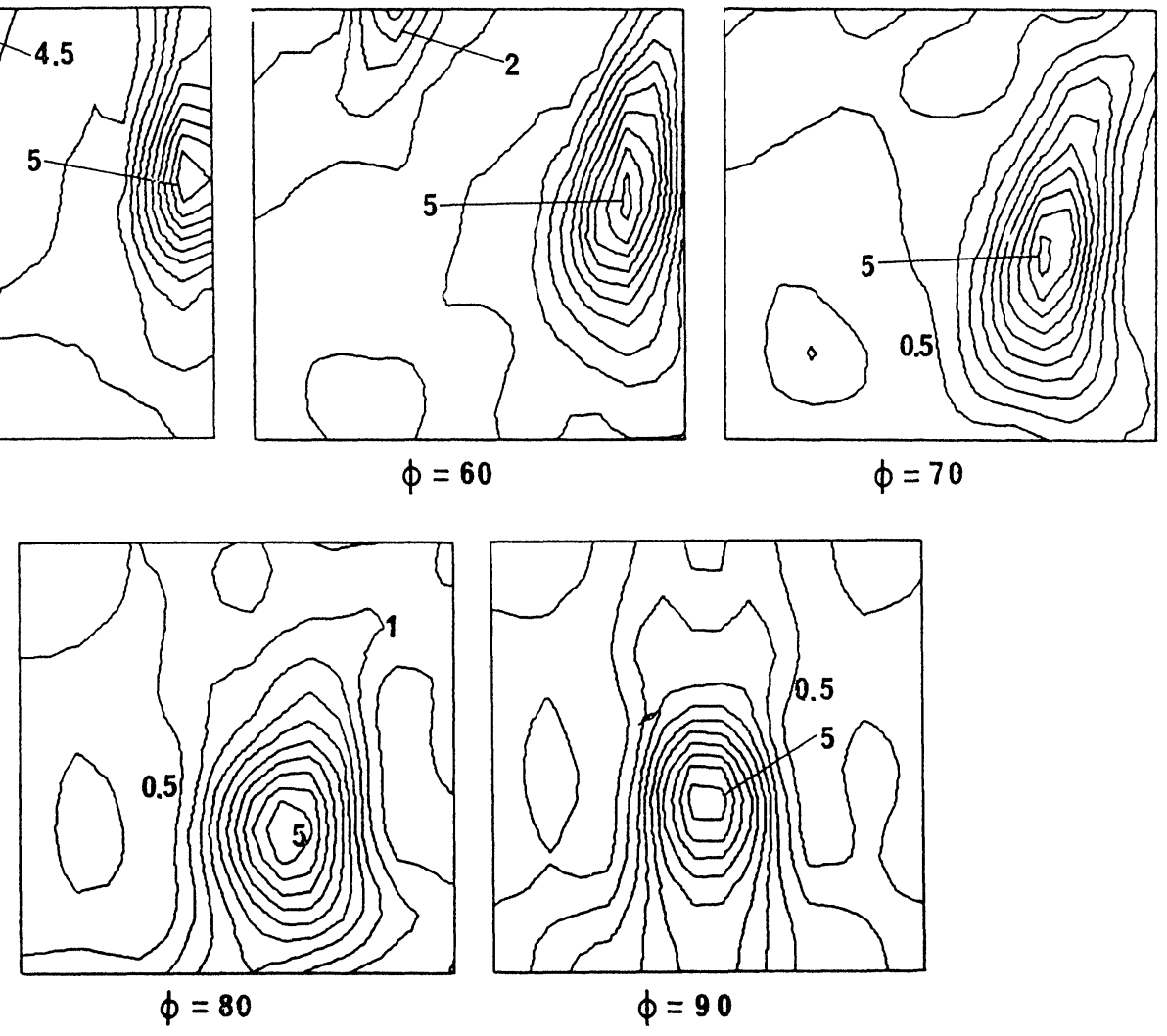

FIGURE 5a 

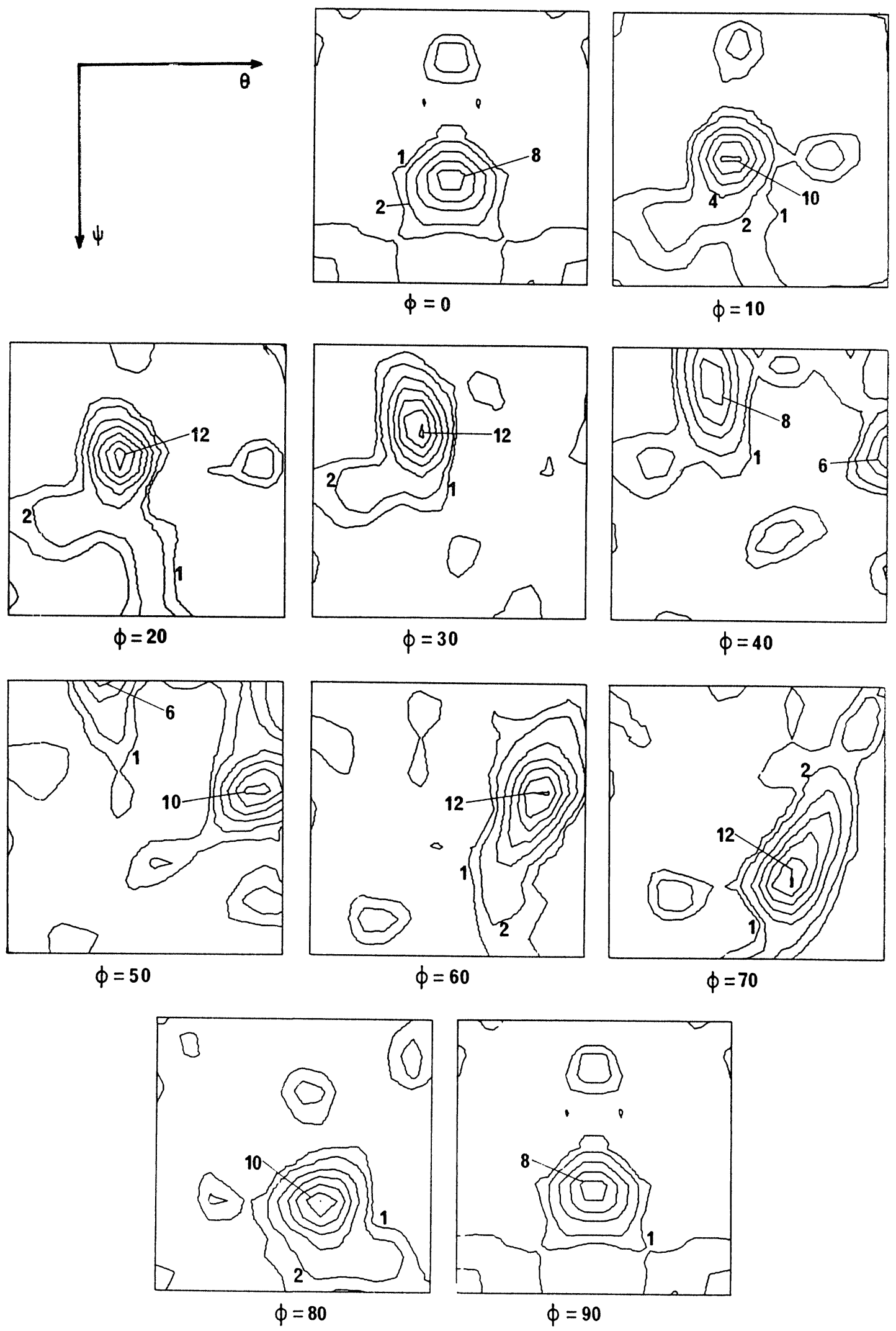

FIGURE $5 b$

FIGURE 5 The crystallite orientation distribution function for cold-rolled copper (a) after 40 per cent reduction (b) after 95 per cent reduction. 



$\phi=50$
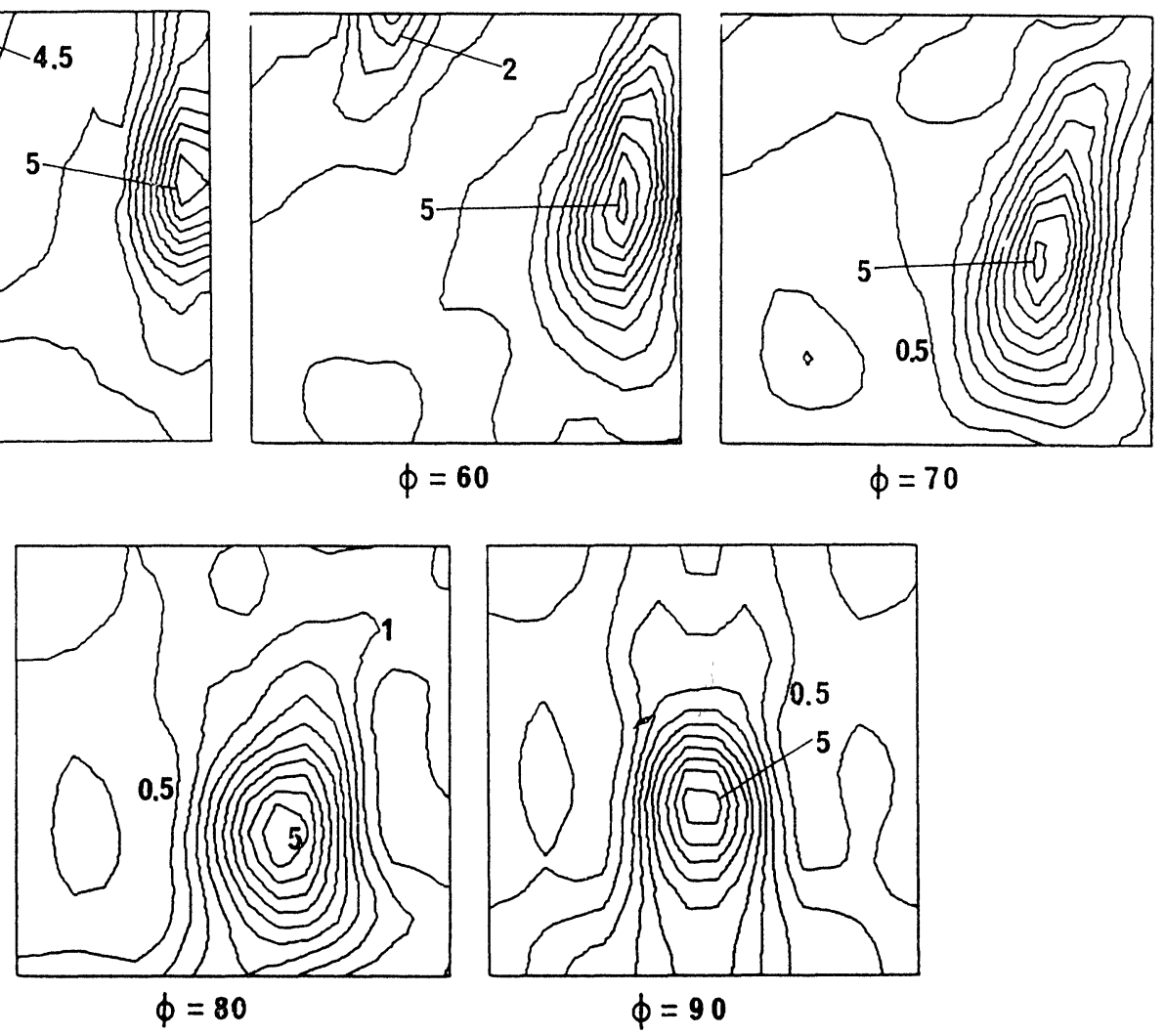

FIGURE 5a 



FIGURE $5 b$

FIGURE 5 The crystallite orientation distribution function for cold-rolled copper (a) after 40 per cent reduction (b) after 95 per cent reduction. 

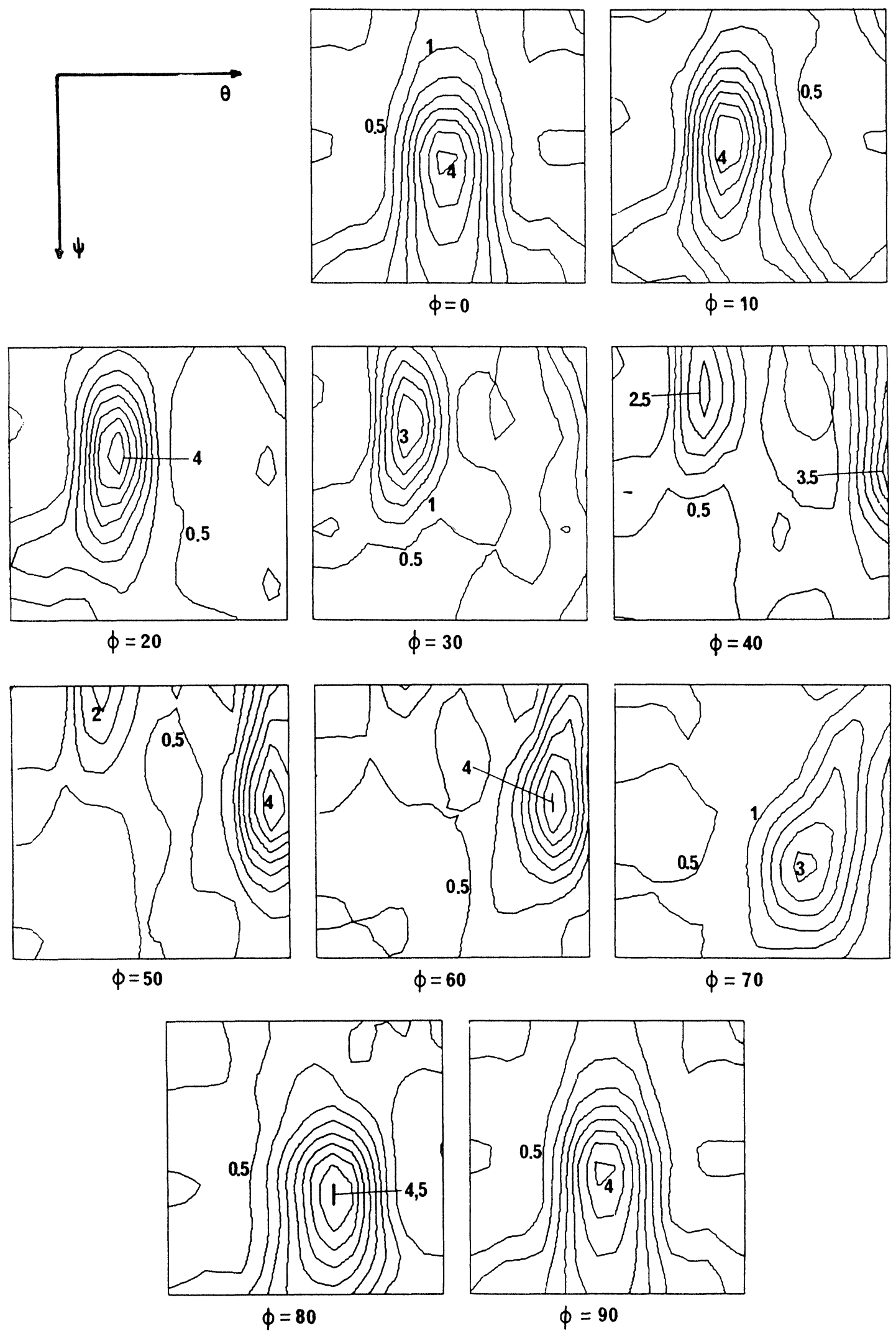

FIGURE 6a 

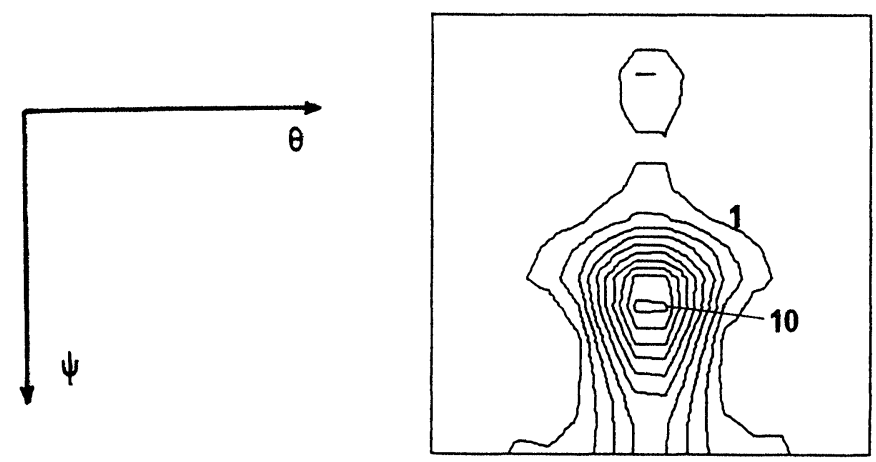

$\phi=0$

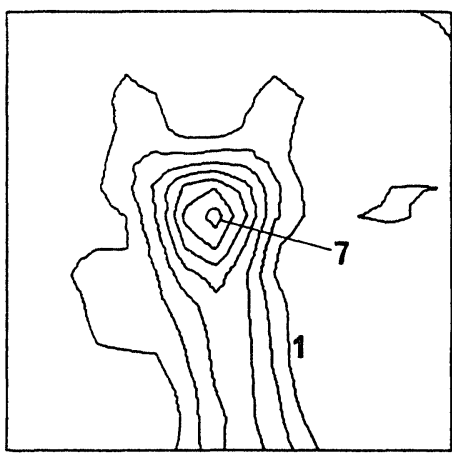

$\phi=20$
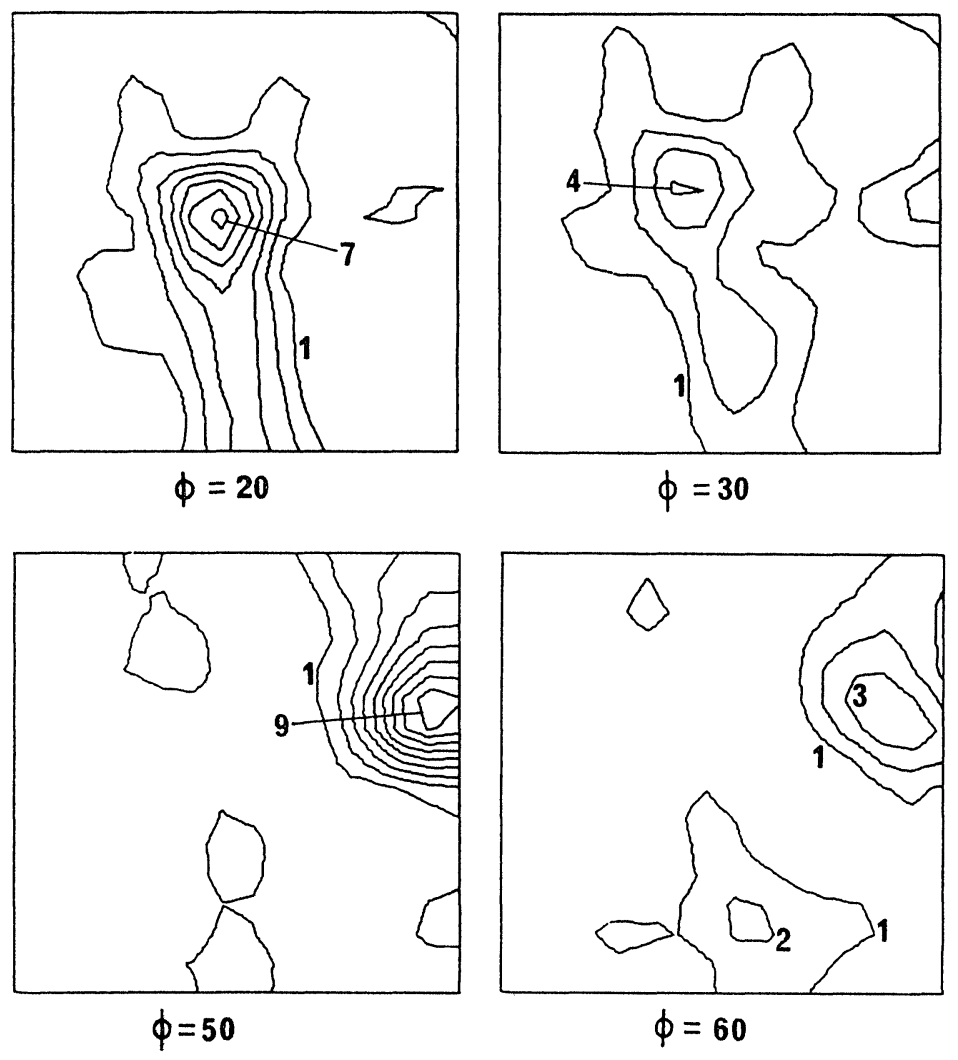

$\phi=30$
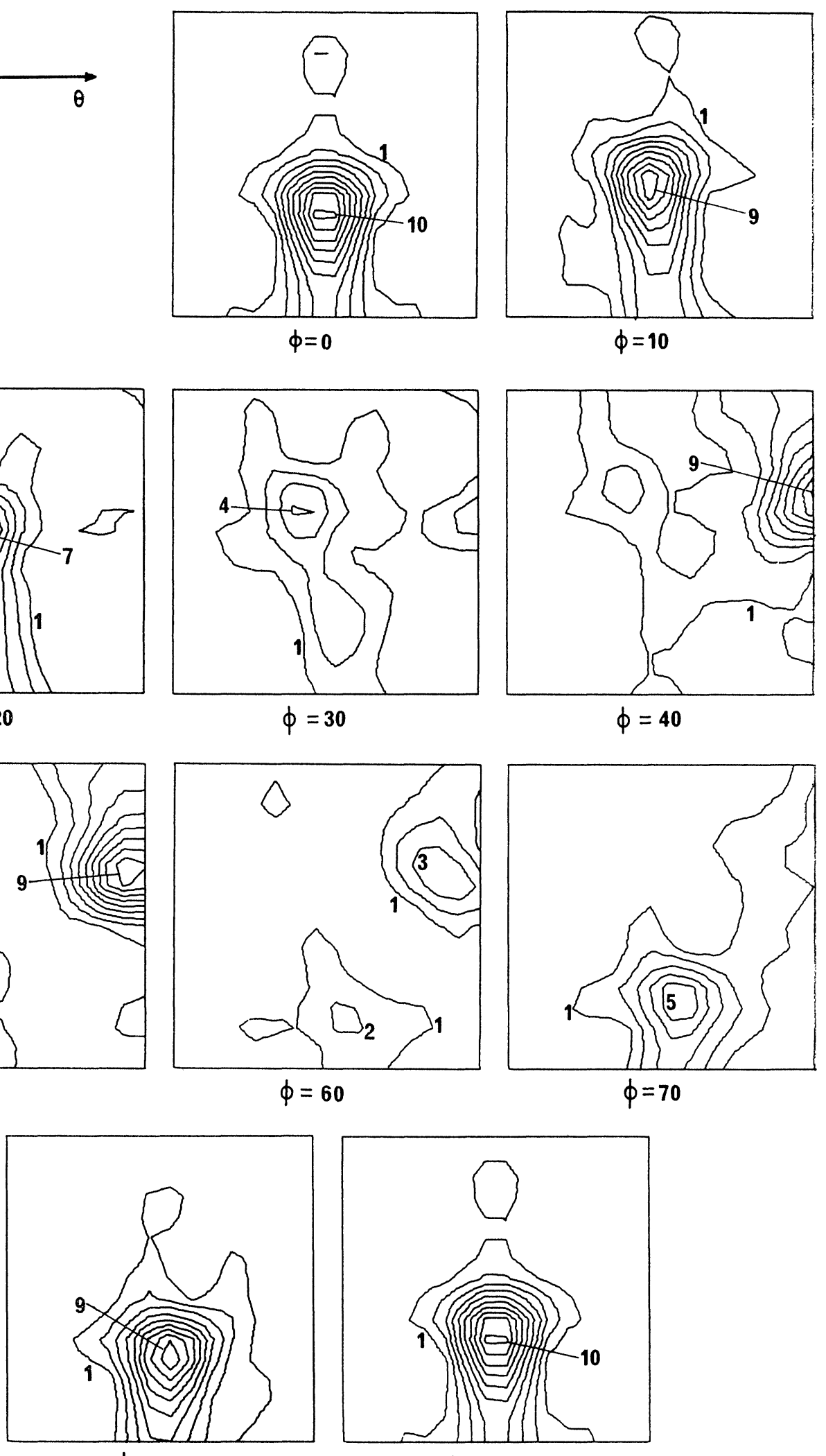

$\phi=80$

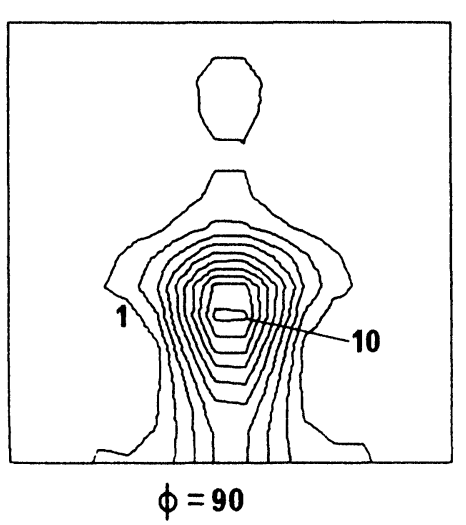

$\phi=90$

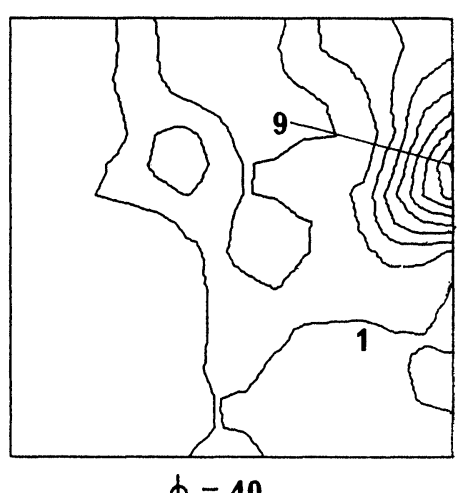

$\phi=\mathbf{4 0}$

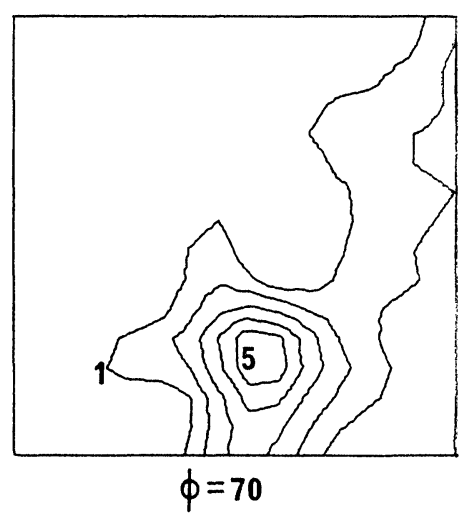

FIGURE $6 b$

FIGURE 6 The crystallite orientation distribution function for cold-rolled copper-10\% zinc (a) after 40 per cent reduction (b) after 95 per cent reduction. 



FIGURE 7a 



FIGURE 7b

FIGURE 7 The crystallite orientation distribution function for cold-rolled copper-30\% zinc (a) after 40 per cent reduction (b) after 95 per cent reduction. 
amount of material associated with the $\{110\}$ $\langle 112\rangle$ orientation is more nearly equal in the three materials than Figure 8 suggests. This is due to the greater orientation spread in the copper- $10 \%$ zinc and copper- $30 \%$ zinc textures. The correlation of the disappearance of material from the region of $\{4411\}\langle 11118\rangle$ orientation with the appearance of material in the vicinity of $\{552\}\langle 115\rangle$ is quite apparent. It is significant to note that the total volume of crystallites associated with the principal texture components is comparatively small. This is in agreement with the findings of Williams ${ }^{30}$ and Kallend and Davies ${ }^{48}$ and further emphasises the inadequacies inherent in the description of textures solely in terms of ideal orientations.

The density of orientations having a [110] transverse direction $\left(\psi=0, \phi=45^{\circ}\right)$ is shown in Figures 9(a) (b) (c). Dillamore et al. ${ }^{13}$ have shown that the choice of $\{111\}\langle 110\rangle$ slip systems for these orientations is unique and that the slip rotations for crystals in these orientations are also uniquely determined. Under conditions of ideal plane strain, orientations with a [110] transverse direction should retain this transverse direction for all slip modes and show a tendency to cluster around the stable orientations near $\{112\}\langle 111\rangle$, $(\{4411\}\langle 11118\rangle)$ and near $\{110\}\langle 001\rangle .{ }^{13}$ This is clearly the case for copper (Figure 9a). On the other hand although the other alloys show indications of the expected behaviour the distribution of orientations is very different from that observed in copper.

These differences in the distributions of orientations can be further emphasised by examining the range of orientations corresponding to the copper orientation tube (Figures 10a, b, c). The initial build-up and subsequent depletion of orientations at the $\{4411\}\langle 11118\rangle$ end of the tube is seen in copper- $10 \%$ zinc and copper- $30 \%$ zinc. For copper the overall shape is maintained to 95 per cent reduction. The change in the relative prominence of the $\{110\}\langle 112\rangle$ and $\{4411\}\langle 11118\rangle$ orientations in the copper between 90 and 95 per cent reduction, although not significant within experimental error, is consistent with predictions ${ }^{2}$ based on the incidence of dynamic recovery.

\subsection{Severity of Texture}

The development of texture in the three materials was quantitatively assessed by calculating the severity parameter (SP) for the different reductions (Figure 11). As described above, a continuous sharpening of the copper texture is evident in contrast with the behaviour of the other two alloys which show a lower rate of texture development.

\section{DISCUSSION}

The present results show that the development of the copper texture (pure metal type) is a continuous process over the range of deformation up to 95 per cent reduction. Increasing the amount of deformation sharpens the texture without affecting the overall shape. The texture is best described as a continuous tube of orientations between $\{110\}$ $\langle 112\rangle$ and $\left\{\begin{array}{llll}4 & 4 & 11\end{array}\right\}\left\langle\begin{array}{llll}11 & 11 & 8\end{array}\right\rangle$. This is not consistent with descriptions of the pure metal texture in terms of mixed discrete components. ${ }^{32}$

The original cross-slip theory of Dillamore and Roberts ${ }^{15}$ predicted a copper texture at high deformations which is consistent with the present results. This theory does not, however, predict the observed development of the copper texture. In the light of the analysis of Dillamore and Roberts it would appear that cross-slip is active during all stages of the deformation process, leading to homogeneous deformation. The existence of homogeneous deformation will promote a sharp final texture, as observed. The observations are also in agreement with the hypothesis ${ }^{23}$ that $\{110\}\langle 112\rangle$ and $\{4411\}\langle 11118\rangle$ should form the extremes of a range of orientations resulting from multiple slip conditions.

The textures of both the copper-zinc alloys show an initial development similar to that seen in copper. However, at reductions of above about 40 per cent there is a marked depletion of orientations at the $\{4411\}\langle 11118\rangle$ end of the orientation tube. At the same time an increase in the density of orientations between $\{111\}\langle 112\rangle$ and $\{110\}\langle 001\rangle$, with considerable spread, is observed. From about 40 per cent reduction onwards the textures of both copper-zinc alloys are markedly less severe than that of copper. The copper-10 per cent zinc alloy shows signs of less reorientation than the copper-30 per cent zinc alloy.

The observed features indicate that an additional deformation mode is present in the copper-30 per cent zinc alloy and to a lesser extent in the copper-10 per cent zinc alloy. The sequence of texture development is contrary to proposals that assume cross-slip as the controlling process. ${ }^{15}$ It is also contrary to the dislocation theory of $\mathrm{Liu}^{32}$. As shown by Dillamore et al. ${ }^{13}$, multiple slip processes cannot lead to the build-up of material 




a

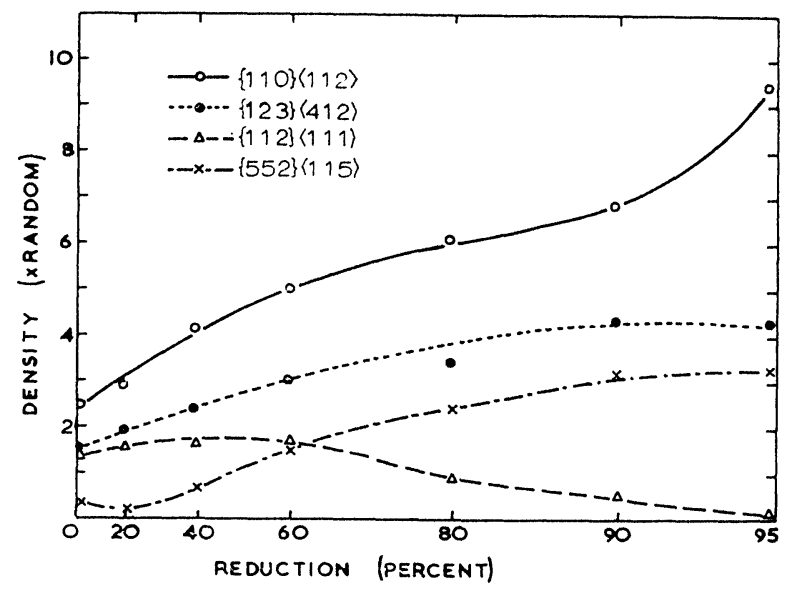

b

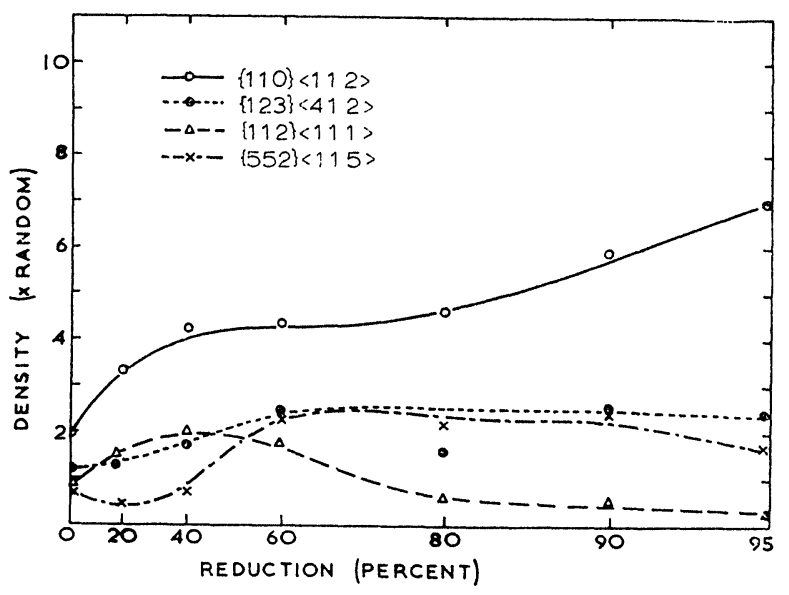

c

FIGURE 8 The variation of orientation density of various ideal orientations with rolling reduction (a) copper (b) copper-10\% zinc (c) copper-30\% zinc. The reduction axis is linear in true strain.

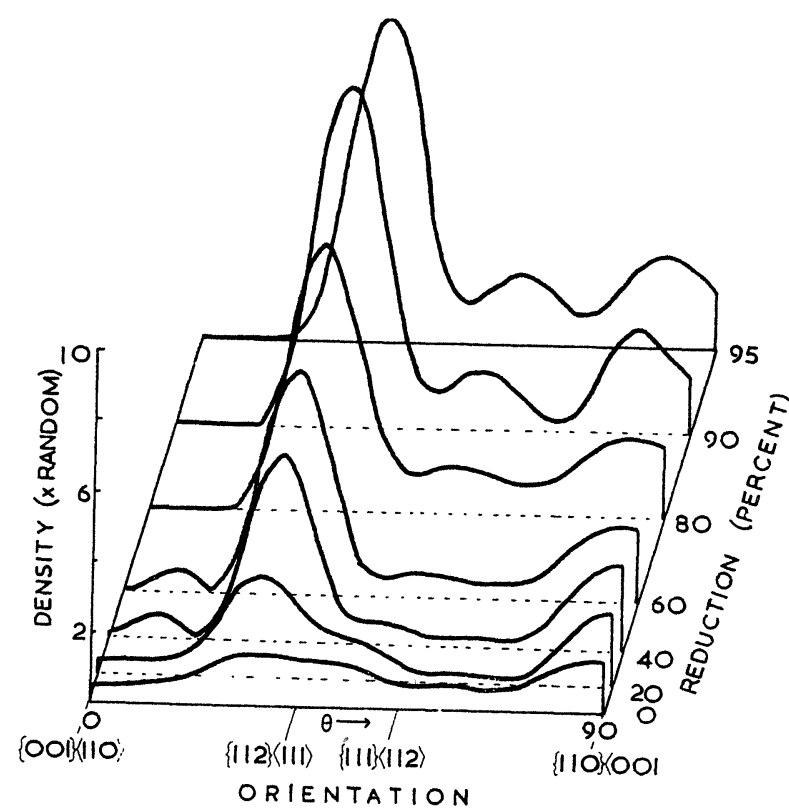

a

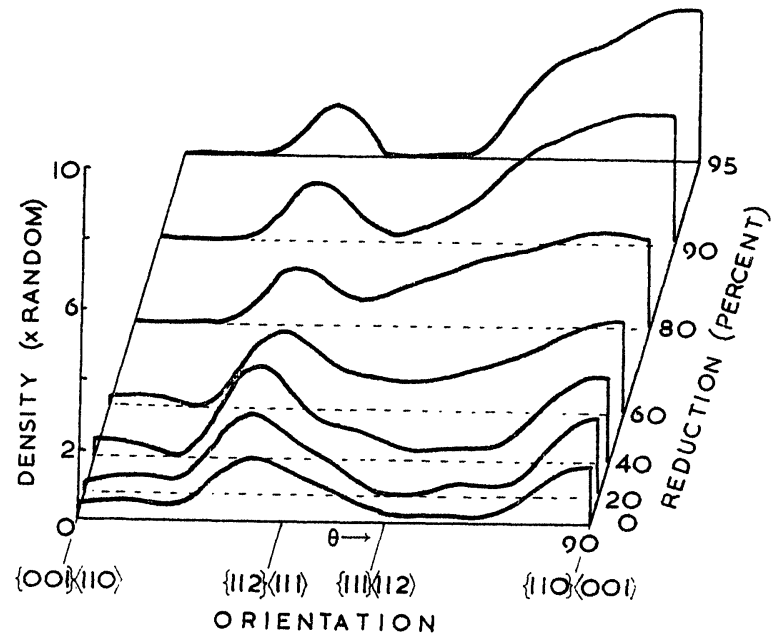

$\mathrm{b}$

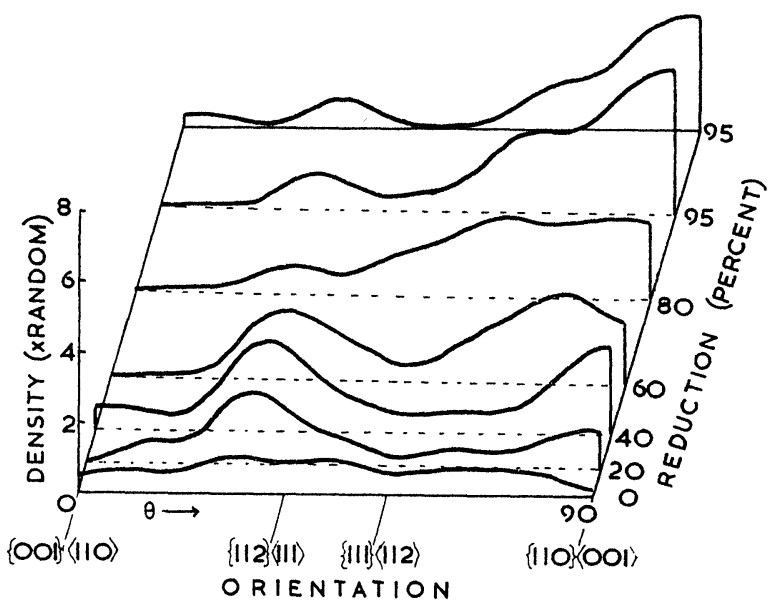

c

FIGURE 9 The variation of orientation density with rolling reduction of orientations having a [110] transverse direction (a) copper (b) copper-10\% zinc (c) copper-30\% zinc. 


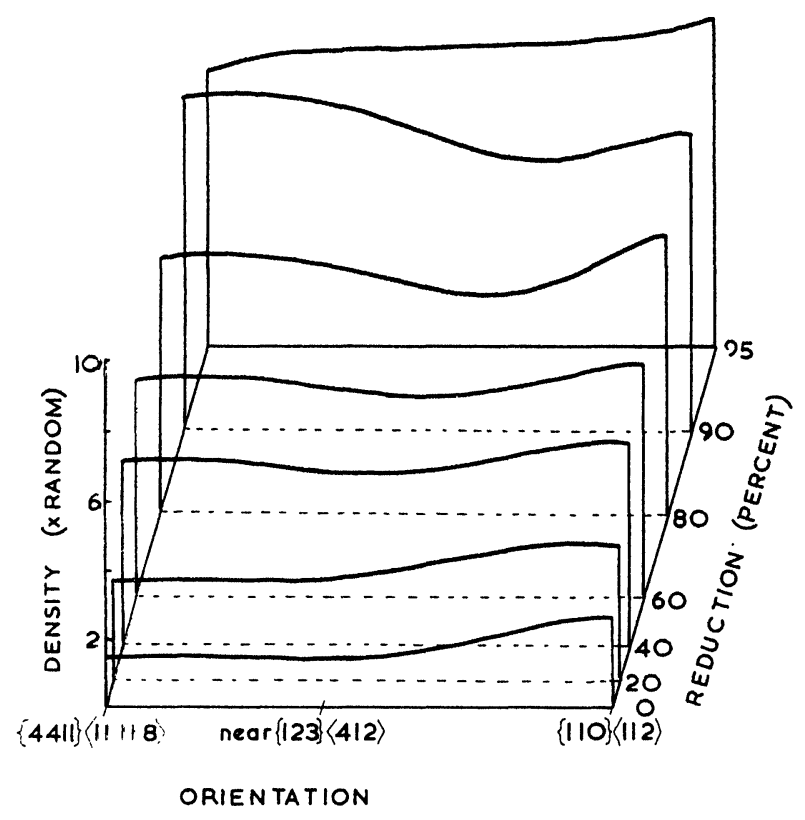

FIGURE 10a



FIGURE 10b



FIGURE 10c

FIGURE 10 The variation of orientation density with rolling reductions of orientations between $\{4411\}\langle 11118\rangle$ and $\{110\}\langle 112\rangle$ for (a) copper (b) copper-10\% zinc (c) copper $-30 \%$ zinc.

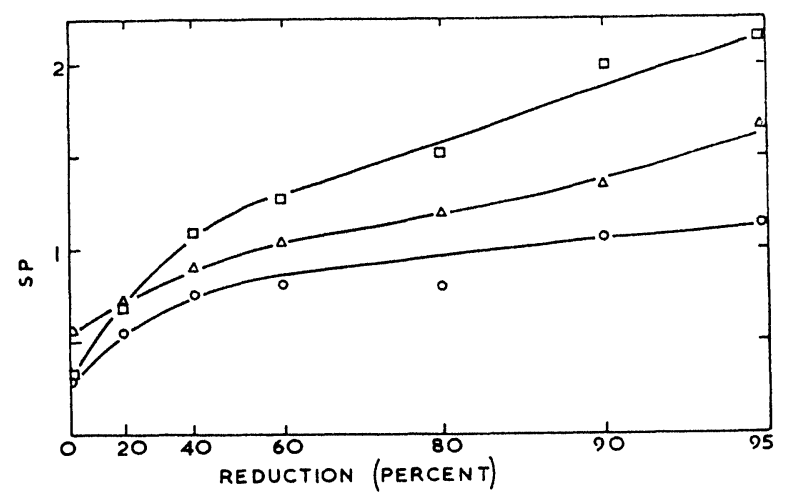

FIGURE 11 Variation of the severity parameter (SP) with reduction $\square$ copper $\triangle$ copper- $10 \%$ zinc $\bigcirc$ copper- $30 \%$ zinc. The reduction axis is linear in true strain. 


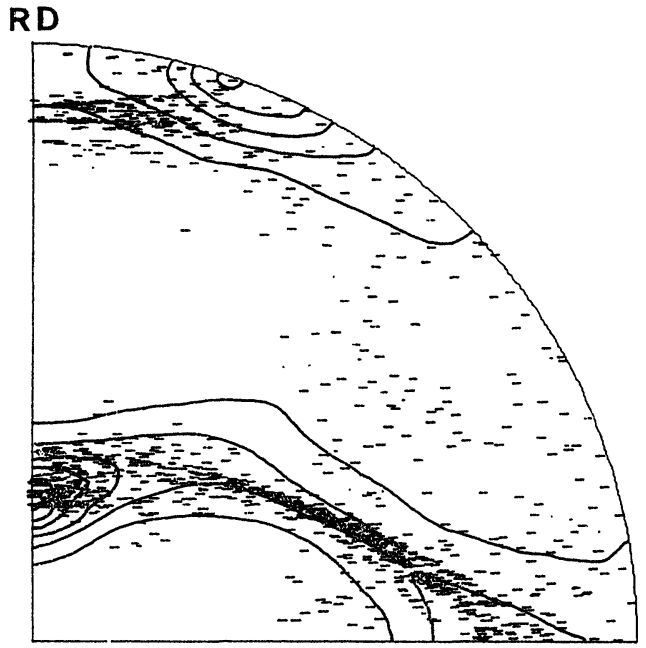

a



b

FIGURE 12 (a) Predicted $\{111\}$ pole figure for the pure metal texture (the cross-slip texture) at 80 per cent reduction with the corresponding experimental pole figure for copper superimposed. (b) Predicted $\{111\}$ pole figure for the alloy texture (the twinning texture) at 80 per cent reduction with the corresponding experimental pole figure for copper-10 per cent zinc superimposed.

in the range $\{111\}\langle 112\rangle$ to $\{552\}\langle 115\rangle$. The existence of material in this orientation range can be explained if mechanical twinning occurs in crystals whose orientations lie at the $\{112\}\langle 111\rangle$ end of the range of orientations which is formed at low deformations. The effect of mechanical twinning is mirror imaging in the twin plane and a rotation due to the shear in a $\langle 112\rangle$ direction. For example, a crystal with a $\{112\}\langle 111\rangle$ orientation would twin to $\{552\}\langle 115\rangle$ and the shear rotation would carry it towards $\{111\}\langle 112\rangle$. Subsequent slip deformation would then take it towards $\{110\}\langle 001\rangle$. All of these orientations were found to be significantly populated at higher deformations in the copper-zinc alloys but not in copper. There is evidence for slip in microtwins ${ }^{2}$ and the observed twins in face-centred cubic alloys have been thin microtwins distributed throughout the crystal. ${ }^{2,20}$ The untwinned portions of the twinned crystals would also be subject to $\langle 112\rangle$ shear rotations which would take them towards $\{111\}\langle 112\rangle$. The same effect could be produced by stacking fault formation, but this mechanism cannot account for the appearance of material in orientations around $\{552\}\langle 115\rangle$.

The increased spread apparent in the textures of the copper-zinc alloys as compared with the texture of copper can arise from two sources. The tendency to form deformation bands is expected to increase as the stacking fault energy is lowered. ${ }^{23}$ This would result in an increased spread about the mean orientation. Further spread would be caused by mechanical twinning since there would be an interaction between two different deformation mechanisms (slip and twinning), each producing different crystal reorientations. The previously recorded dependence of the development of the different textures of the texture transition on stacking fault energy is also in agreement with the existence of increasing amounts of mechanical twinning in the copper-zinc alloys.

As mentioned in Section 1, a detailed analysis simulating texture development incorporating crossslip and allowing for twinning has been carried out $^{51}$. Figure 12 shows two sets of results. The agreement with experiment is extremely good and provides additional support for concluding that mechanical twinning is predominant in determining the differences between the pure metal texture and the alloy texture.

Two other points should be noted. Firstly, a mechanism involving mechanical twinning is in agreement with the observation that the development of the alloy texture is favoured by high strain rates ${ }^{9}$ since the incidence of twinning increases in most metals with increasing strain rate. ${ }^{49}$ 
Secondly, mechanical twinning can account for the temperature dependence of texture transition since the incidence of twinning increases with decreasing temperature ${ }^{50}$ and deformation at low temperatures favours the formation of the alloy texture. $^{3,6}$

\section{CONCLUSIONS}

The crystallite orientation distribution function has been determined for cold-rolled copper, copper-10 per cent zinc and copper-30 per cent zinc ( $\alpha$-brass) at cold reductions of $0,20,40,60,80,90$ and 95 per cent. The copper texture exhibits a steady development and contains a tube of orientations between limits which have previously been shown to be stable during multiple slip processes $(\{110\}$ $\langle 112\rangle$ to $\left.\left\{\begin{array}{lll}4 & 41\end{array}\right\}\langle 11118\rangle\right)$. The textures of the copper-zinc alloys both show a similar initial development to that of copper but a transition occurs above a reduction of about 40 per cent. This indicates that an additional deformation mode has become active. The features of the transition are consistent with those expected if the additional deformation mode were mechanical twinning. The development of the basic texture (pure-metal type) is in agreement with predictions based on the assumption of multiple slip conditions incorporating a considerable amount of cross-slip.

\section{ACKNOWLEDGEMENTS}

The authors wish to thank the Director of the University Computing Service for the use of the TITAN computer. During the work one of them (J.S.K.) was supported by a Science Research Council Grant which he gratefully acknowledges.

\section{REFERENCES}

1. I. L'. Dillamore and W. T. Roberts, Met. Reviews 10, 271 (1965).

2. H.Hu, R.S. Cline and S. R. Goodman, Recrystallisation, Grain Growth and Textures (ASM Metals Park, Ohio, 1966), p. 295.

3. R. E. Smallman, J. Inst. Metals 84, 10 (1955-1956).

4. Y. C. Liu and R. H. Richman, Trans. TMS-AIME 218, 688 (1960).

5. R. H. Richman and Y. C. Liu, Trans. TMS-AIME 221, 720 (1961).

6. H. Mueller, Osterr. Akad. wiss. Math. Naturw. 7, 117 (1958).

7. H.Hu and R. S. Cline, J. Appl. Phys. 32, 760 (1961).

8. H. Hu, R. S. Cline and S. R. Goodman, J. Appl. Phys. 32, 1392 (1961).

9. T. Leffers, Scripta Met . 2, 447 (1968).

10. S. R. Goodman and H. Hu, Trans. TMS-AIME 230 , 1413 (1964).
11. R. E. Smallman and D. Green, Acta Met. 12, 145 (1964).

12. I. L. Dillamore, R. E. Smallman and W. T. Roberts Phil. Mag. 9, 517 (1964).

13. I. L. Dillamore, E. Butler and D. Green, Met. Sci. J. 2, 161 (1968).

14. T. Leffers and A. Grum-Jensen, Trans. TMS-AIME 242, 314 (1968).

15. I. L. Dillamore and W. T. Roberts, Acta Met. 12, 281 (1964).

16. A. Seeger, Dislocations and Mechanical Properties of Crystals (John Wiley, New York, p, . 1957), 243.

17. P. R. Thornton, T. E. Mitchell and P. B. Hirsch, Phil. Mag. 7, 1349 (1962).

18. D. Kuhlmann-Wilsdorf and H. Wilsdorf, Acta Met. 1, 394 (1953).

19. T. Leffers, Z. Metallke 60, 785 (1969).

20. D. M. Turley, J. Inst. Metals 97, 237 (1969).

21. H. Hu and P. A. Beck, J. Metals 2, 1214 (1950).

22. H. Hu, P. R. Sperry and P. A. Beck, Trans. AIME 194, $76(1952)$.

23. I. L. Dillamore, Met.Trans. 1, 2463 (1970).

24. F. Haessner, Z. Metallke 54, 98 (1963).

25. T. Ll. Richards and S. F. Pugh, J. Inst. Metals 88, 399 (1959-60).

26. C. J. Beevers and R. W. K. Honeycombe, Acta Met. 9, $513(1961)$

27. G. Wassermann, Z. Metallke 54, 61 (1963).

28. H. Ahlborn, J. Grewen and G. Wassermann, Z. Metallke 55, $598(1964)$.

29. W. Heye and G. Wassermann, Phys. Stat. Sol. 18, K107 (1966).

30. R. O. Williams, Trans. TMS-AIME 242, 105 (1968).

31. G. Y. Chin, W. F. Hosford and D. R. Mendorf, Proc Roy. Soc. A309, 433 (1969).

32. Y. C. Liu, Trans. TMS-AIME 230, 656(1964).

33. H-J. Bunge and F. Haessner, J. Appl. Phys. 39, 5503 (1968).

34. G. A. Alers and Y. C. Liu, Trans. TMS-AIME 239, 210 (1967).

35. I. L. Dillamore, Trans. TMS-AIME 233, 1198 (1965).

36. G.I. Taylor, J. Inst. Metals 62, 307 (1938).

37. J. F. W. Bishop and R. Hill, Phil. Mag. 42, 414 (1951).

38. J. F. W. Bishop and R. Hill, Phil. Mag. 42, 1298 (1951).

39. G. Y. Chin, in Textures in Research and Practice (Springer, Berlin, 1969), p. 51.

40. I. L. Dillamore and N. S. Stoloff, in Textures in Research and Practice (Springer, Berlin, 1969), p. 110.

41. S. Leber, Rev. Sci. Instrum. 36, 1747 (1965).

42. J. A. Elias and A. J. Heckler, Trans. TMS-AIME 239, 1237 (1967).

43. L. G. Schultz, J. Appl. Phys. 20, 1030 (1949).

44. S. L. Lopata and E. B. Kula, Trans. TMS-AIME 224, 865 (1962).

45. R. J. Roe, J. Appl. Phys. 36, 2024 (1965).

46. H-J. Bunge and W. T. Roberts, J. Appl. Cryst. 2, 116 (1969).

47. G. J. Davies, D. J. Goodwill and J. S. Kallend, J. Appl. Cryst. 4, 67 (1971).

48. J. S. Kallend and G. J. Davies, J. Inst. Met. 97, 350 (1969).

49. R. L. Nolder and G. Thomas, Acta Met. 11, 994 (1963).

50. P. R. Thornton and T. E. Mitchell, Phil. Mag. 7, 361 (1962).

51. J. S. Kallend and G. J. Davies, Phil. Mag. 25, 471 (1972). 